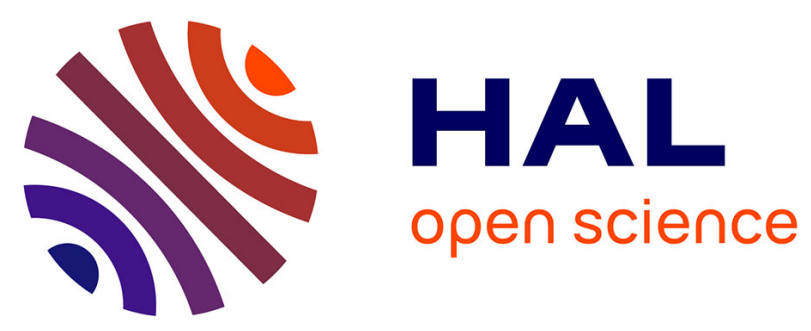

\title{
Structure and photoluminescence properties of evaporated GeOx thin films
}

\author{
M. Ardyanian, H. Rinnert, X. Devaux, M. Vergnat
}

\section{To cite this version:}

M. Ardyanian, H. Rinnert, X. Devaux, M. Vergnat. Structure and photoluminescence properties of evaporated GeOx thin films. Applied Physics Letters, 2006, 89, pp.011902. 10.1063/1.2218830 . hal-02164231

\section{HAL Id: hal-02164231 \\ https://hal.science/hal-02164231}

Submitted on 24 Jun 2019

HAL is a multi-disciplinary open access archive for the deposit and dissemination of scientific research documents, whether they are published or not. The documents may come from teaching and research institutions in France or abroad, or from public or private research centers.
L'archive ouverte pluridisciplinaire HAL, est destinée au dépôt et à la diffusion de documents scientifiques de niveau recherche, publiés ou non, émanant des établissements d'enseignement et de recherche français ou étrangers, des laboratoires publics ou privés. 


\title{
Structure and photoluminescence properties of evaporated $\mathrm{GeO}_{x}$ thin films
}

\author{
M. Ardyanian, H. Rinnert, X. Devaux, and M. Vergnat ${ }^{\mathrm{a})}$ \\ Laboratoire de Physique des Matériaux (UMR CNRS No. 7556), Université de Nancy 1, Boîte Postale 239, \\ 54506 Vandouvre-lès-Nancy Cedex, France
}

(Received 27 February 2006; accepted 16 May 2006; published online 5 July 2006)

\begin{abstract}
Amorphous $\mathrm{GeO}_{x}$ alloys were prepared by evaporation of $\mathrm{GeO}_{2}$ powder on substrates maintained at $100{ }^{\circ} \mathrm{C}$. The evolution of the structure was investigated by infrared-absorption spectrometry, Raman spectrometry and transmission electron microscopy experiments for annealing temperatures less than $600{ }^{\circ} \mathrm{C}$. These experiments allowed us to follow the phase separation of the alloy and to observe the appearance of amorphous and crystallized Ge aggregates. The evolution of the photoluminescence in the range of 560-1550 nm was correlated to the structure of the films.

(C) 2006 American Institute of Physics. [DOI: 10.1063/1.2218830]
\end{abstract}

During the last ten years, silicon, germanium, or silicongermanium quantum dots embedded in an insulator have been studied extensively for their new physical properties induced by the size reduction. They have potential applications for optoelectronic devices or for single-electron devices such as memories. In particular, the optical properties of nanostructures made from silicon or germanium have attracted much attention because it opens new possibilities for optoelectronic applications with group IV elements. Indeed the confinement of carriers in such structures with sizes lower than the exciton Bohr radius leads to a strong enhancement of the radiative transition yield and to the increase of the emitted photons energy.

Silicon nanocrystals can be obtained in substoichiometric $\mathrm{SiO}_{x}$ films prepared by $\mathrm{Si}$ implantation in $\mathrm{SiO}_{2}{ }^{1,2}$ plasma enhanced chemical vapor deposition, ${ }^{3}$ sputtering, ${ }^{4}$ or evaporation. ${ }^{5,6}$ In such silicon suboxides, the silicon clusters are generated by annealing posttreatments which involve in the demixtion of the $\mathrm{SiO}_{x}$ film following the reaction $\mathrm{SiO}_{x} \rightarrow \mathrm{Si}+\mathrm{SiO}_{2}$.

Such studies have also been performed to follow the formation of Ge nanocrystals during annealing treatments in $\mathrm{SiGeO}_{x}$ alloys or in $\mathrm{GeO}_{x}$ films prepared by magnetron sputtering, ${ }^{7}$ but there has been very little work done on the PL properties of the Ge nanostructures. In this letter, we report on a study of $\mathrm{GeO}_{x}$ thin films prepared by evaporation of $\mathrm{GeO}_{2}$ grains. It is shown that annealing treatments enables us to obtain $\mathrm{Ge}$ nanocrystals in a $\mathrm{GeO}_{2}$ matrix. The PL properties are correlated to the evolution of the structure, in particular, to the growth of the nanocrystals.

$\mathrm{GeO}_{2}$ was evaporated in a high-vacuum chamber from an electron beam gun. The base pressure was $10^{-8}$ Torr. The pressure during the evaporation increases until $3 \times 10^{-6}$ Torr. The silicon substrates were maintained at $100{ }^{\circ} \mathrm{C}$. The deposition rate of $0.1 \mathrm{~nm} / \mathrm{s}$ was controlled by a quartz microbalance. The layer thickness was $200 \mathrm{~nm}$. After deposition, the films were annealed in a high-vacuum quartz tube with a tubular oven. The heating rate was $10{ }^{\circ} \mathrm{C} \mathrm{min}-1$. When the annealing temperature $T_{a}$ was reached, this oven was pushed away and the films cooled naturally.

The evolution of the atomic structure and of the oxygen bonding configurations was followed by infrared (IR) ab-

${ }^{a)}$ Electronic mail: vergnat@lpm.u-nancy.fr sorption spectroscopy, Raman spectroscopy and transmission electron microscopy (TEM) observations. The normal incidence IR absorption measurements were carried out with a resolution of $4 \mathrm{~cm}^{-1}$. The baseline of the spectra was subtracted. Raman measurements were achieved with a multichannel spectrometer equipped with a 1800 grooves $/ \mathrm{mm}$ grating. The $488 \mathrm{~nm}$ excitation light source was emitted by an argon laser.

Photoluminescence excitation at $355 \mathrm{~nm}$ was performed using a frequency-trippled YAG (yttrium aluminum garnet):Nd laser. Optical emission was analyzed by a monochromator equipped with a 600 grooves $/ \mathrm{mm}$ grating and by a near infrared photomultiplier tube cooled at $190 \mathrm{~K}$. The time resolution of the system is around $10 \mathrm{~ns}$. The response of the detection system was precisely calibrated with a tungsten wire calibration source. For PL measurements, the films were maintained at $77 \mathrm{~K}$.

Figure 1 presents the IR absorption spectra of the samples as-deposited and annealed at different temperatures $T_{a}$. Only the range of $400-1200 \mathrm{~cm}^{-1}$ is presented since the $\mathrm{Ge}-\mathrm{OH}$ bonds are not visible around $3400 \mathrm{~cm}^{-1}$. For the as-deposited sample, two intense $\mathrm{Ge}-\mathrm{O}$ bands are observed at 524 and $825 \mathrm{~cm}^{-1}$. They are assigned to the $\mathrm{Ge}-\mathrm{O}-\mathrm{Ge}$ bending vibration mode and to the stretching vibration mode of the same group, respectively. ${ }^{8}$ With annealing, the absorption intensity of these $\mathrm{Ge}-\mathrm{O}-\mathrm{Ge}$ bands increases and their frequency shifts towards higher wave numbers (from 524 to $570 \mathrm{~cm}^{-1}$ and from 824 to $870 \mathrm{~cm}^{-1}$, respectively). Such a shift has already been observed in substoichiometric $\mathrm{SiO}_{x}$ alloys by several groups ${ }^{9,10}$ which have shown that the

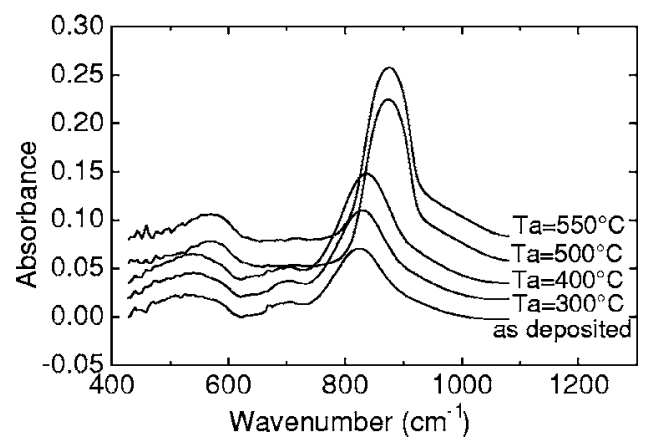

FIG. 1. IR absorption spectra of the $\mathrm{GeO}_{x}$ films annealed at different temperatures $T_{a}$. 


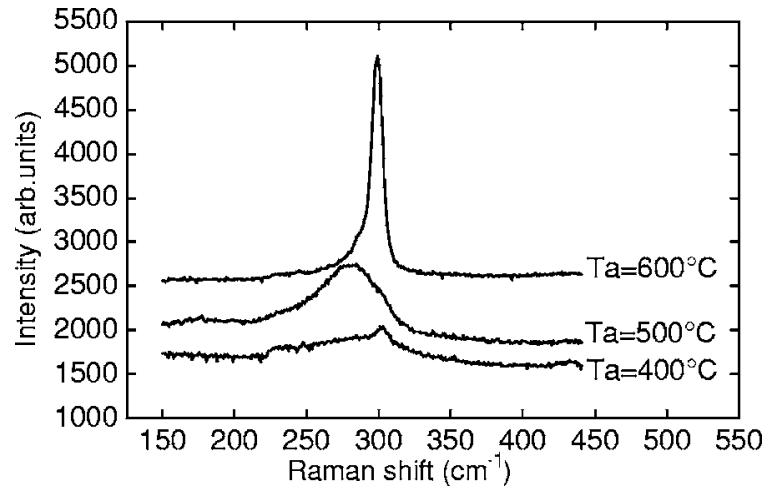

FIG. 2. Raman spectrometry spectra of $\mathrm{GeO}_{x}$ films annealed at different temperatures $T_{a}$.

frequency of these peaks increases with the oxygen composition of the films, due to the strong electronegativity of the second-nearest-neighbor oxygen atoms.

Therefore, during evaporation, there is partial decomposition of the $\mathrm{GeO}_{2}$ source by the electron beam, which explains the increase of the pressure in the chamber, and the deposited films are substoichiometric. Moreover, the shift of the peaks towards higher frequencies shows that the suboxide evolved into the Ge dioxide phase. As the average chemical composition remains unchanged, it can be concluded that a phase separation appears in the film and that pure Ge or Ge-rich areas appear in the samples, following the reaction $\mathrm{GeO}_{x} \rightarrow \mathrm{Ge}+\mathrm{GeO}_{2}$. It is difficult to say whether the decomposition is finished for $T_{a}$ equal to $550{ }^{\circ} \mathrm{C}$, but the measured values of the peaks positions are slightly higher than those obtained for thin films by Lucovsky et al. ${ }^{8}[560$ and $860 \mathrm{~cm}^{-1}$ in $a-\mathrm{Ge}:(\mathrm{O}-\mathrm{H})$ alloys prepared by glow discharge of germane with water vapor] and by Busani et al. ${ }^{11}$ (561 and $858 \mathrm{~cm}^{-1}$ for an anodic oxide). Moreover, it was not possible to study the structure for annealing temperatures higher than $600{ }^{\circ} \mathrm{C}$. Indeed, for these temperatures, the peaks shift towards lower wave numbers and their intensity decreases because the germanium oxide phase becomes volatile.

Another weak absorption band is visible near $700 \mathrm{~cm}^{-1}$ for the as-deposited film and the film annealed at $300{ }^{\circ} \mathrm{C}$. As proposed by Busani et al., ${ }^{12}$ this band is probably a stretching mode of dangling $\mathrm{GeO}$ bonds. This hypothesis is confirmed by the disappearance of this band for the higher annealing temperatures which generally corresponds to a densification of the atomic structure and the disappearance of the dangling bonds.

Raman spectroscopy is a very efficient method to observe the presence of $\mathrm{Ge}$ on its crystalline or amorphous form. Bulk crystalline Ge is characterized by an intense and thin band at $300 \mathrm{~cm}^{-1}$, which corresponds to the transverse optic (TO) mode of phonons. In the case of amorphous Ge, the disorder changes the vibrational density of states and the Raman spectrum ${ }^{13}$ is characterized by a broad band at $270 \mathrm{~cm}^{-1}$.

Figure 2 shows Raman shifts of $\mathrm{GeO}_{x}$ films annealed at different temperatures $T_{a}$. For $T_{a}$ less than $400{ }^{\circ} \mathrm{C}$, the spectrum only shows very weak bands at 300 and $430 \mathrm{~cm}^{-1}$ which correspond to the vibrational modes of the crystalline silicon substrate. This means that the films do not contain Ge aggregates. For $T_{a}$ equal to $500{ }^{\circ} \mathrm{C}$, the spectrum shows the signal of the film, i.e., a broad band at $270 \mathrm{~cm}^{-1}$, corresponding to the presence of an amorphous phase of Ge. For $T_{a}$ Downloaded 06 Jul 2006 to 194.214.217.17. Redistribution subject

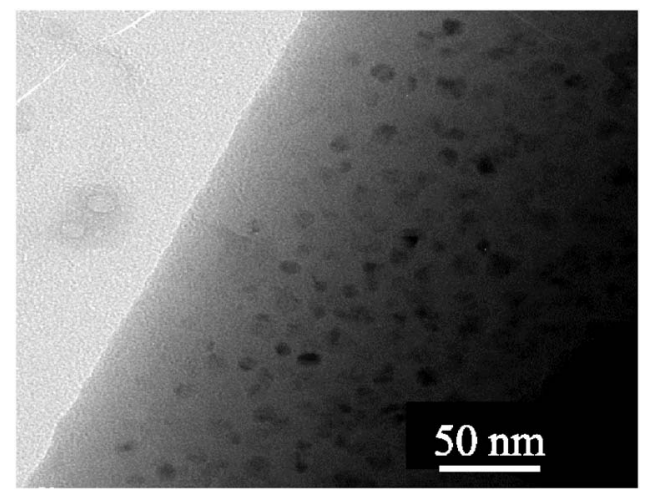

FIG. 3. TEM micrograph of a $\mathrm{GeO}_{x}$ film annealed at $600{ }^{\circ} \mathrm{C}$.

equal to $600{ }^{\circ} \mathrm{C}$, the amorphous peak disappears and a sharp peak appears at $300 \mathrm{~cm}^{-1}$, which corresponds to the formation of crystalline Ge. The peak presents a low-frequency asymmetric broadening, which suggests the presence of nanocrystals. ${ }^{14}$ The presence of a crystallized $\mathrm{GeO}_{2}$ phase, characterized by a Raman $\operatorname{shift}^{15}$ at $440 \mathrm{~cm}^{-1}$, was not observed.

These results are in agreement with the IR spectrometry results. They strongly suggest that a phase separation process happens in the films to form the two more stable $a$-Ge and $a-\mathrm{GeO}_{2}$ phases. For $T_{a}$ equal to $600{ }^{\circ} \mathrm{C}$, the $\mathrm{Ge}$ phase is crystallized but the $\mathrm{GeO}_{2}$ phase remains amorphous.

TEM micrographs confirm these results. Whereas the samples annealed at $500{ }^{\circ} \mathrm{C}$ show micrographs and diffraction patterns typical of an amorphous phase, the micrographs of the samples annealed at $600{ }^{\circ} \mathrm{C}$ show nanocrystals with sizes of a few nanometers (Fig. 3) and their diffraction patterns show the diffraction lines corresponding to crystalline Ge.

Figure 4 presents PL spectra of $\mathrm{GeO}_{x}$ films annealed at different temperatures $T_{a}$. For the films as-deposited and annealed at 300 and $350{ }^{\circ} \mathrm{C}$, the PL spectra show a very broad band between 560 and $1550 \mathrm{~nm}$, with an intense and narrow band near $1000 \mathrm{~nm}$. The typical decay time of these bands are below $20 \mathrm{~ns}$. As theses bands are proportional, they must have the same origin. Their intensity slightly increases with $T_{a}$ until $350{ }^{\circ} \mathrm{C}$. For $T_{a}$ equal to 400 and $450{ }^{\circ} \mathrm{C}$, these bands disappear and another weaker and broad band appears with a maximum near $1250 \mathrm{~nm}$ and with a typical decay time equal to $200 \mathrm{~ns}$. This band redshifts near $1400 \mathrm{~nm}$ for $T_{a}$

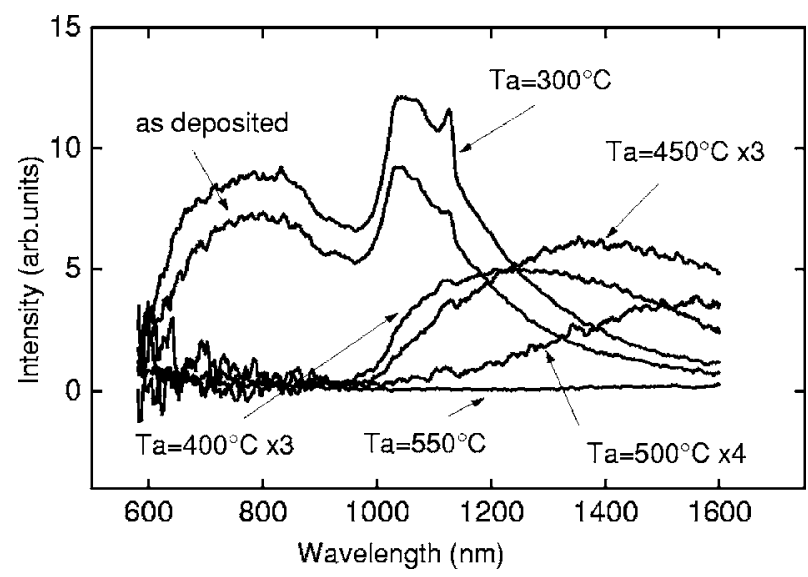

FIG. 4. PL spectra of $\mathrm{GeO}_{x}$ films annealed at different temperatures $T_{a}$. AIP license or copyright, see http://apl.aip.org/apl/copyright.jsp 
equal to $500{ }^{\circ} \mathrm{C}$ and there is no more PL for $T_{a}$ equal to $550{ }^{\circ} \mathrm{C}$.

To understand the origin of these bands, it must be to recall that the PL of Si nanocrystals has mainly two components: a "blue" one generally associated with defects in the surrounding oxide and a "red" one coming either from the recombination of electron-hole pairs in nanocrystals or from the trapping on a surface defect. ${ }^{16}$ In comparison to silicon, there has been little work done on Ge nanostructures and PL has been observed mainly in Ge nanocrystals embedded in $\mathrm{SiO}_{2}$ matrices. There are several reports of a "blue-green" PL with a maximum below $620 \mathrm{~nm}$ independently of the size of the nanocrystals. ${ }^{17}$ For example, Kartopu et al. ${ }^{18}$ have observed, in a spark-processed Ge, a broad "orange" band between 520 and $820 \mathrm{~nm}$ attributed to defects in the $\mathrm{GeO}_{x}$ phase. But recently, Takeoka et al. ${ }^{19}$ have observed a sizedependent PL in the near-infrared region which is closer to the band gap of bulk Ge and which is more compatible with the quantum confinement model.

The broad band observed in our samples as-deposited and annealed at 300 and $350{ }^{\circ} \mathrm{C}$ is rather similar to the bands generally attributed to the defects in the oxide phase. With annealing at temperatures higher than $400{ }^{\circ} \mathrm{C}$, IR absorption experiments have shown that there is a strong modification of the structure, characterized by an important shift of the stretching vibration band and by the disappearance of the $700 \mathrm{~cm}^{-1}$ band attributed to defects. This last result is in agreement with the suppression of this broad PL band for $T_{a}$ equal to $400{ }^{\circ} \mathrm{C}$. Moreover, the fast PL decay time of this band is typical of defects luminescence.

After this structural modification, it remains (or it appears) a weak band with a maximum near $1240 \mathrm{~nm}$ for $T_{a}$ equal to $400{ }^{\circ} \mathrm{C}$. This band redshifts with increasing $T_{a}$ with energy slightly higher than the band gap of Ge. Its observation corresponds to the phase separation of the alloys and to the appearance of the amorphous Ge aggregates, as shown by the IR absorption and Raman spectrometry experiments. Its redshift with increasing $T_{a}$ and therefore with increasing aggregates size is in agreement with the quantum-confinement theory. Moreover, the measured PL decay time of this band is in agreement with the lifetimes values predicted by Niquet $e t$ $a l .{ }^{17}$ for Ge nanocrystals. This PL band could then be attributed to the Ge aggregates.
In conclusion, visible and near-infrared PLs can be observed in $\mathrm{GeO}_{x}$ films prepared by evaporation of $\mathrm{GeO}_{2}$ powder from an electron beam gun. With thermal annealing, the films present a phase separation inducing the appearance of $\mathrm{Ge}$ aggregates in a $\mathrm{GeO}_{2}$ matrix. The evolution of the IR absorption and Raman spectrometries correlated to the PL experiments suggests that the PL originates in the presence of defects in the oxide matrix for annealing temperatures less than $350{ }^{\circ} \mathrm{C}$ and in the $\mathrm{Ge}$ aggregates for higher annealing temperatures.

The authors wish to acknowledge F. Mouginet and J. Arocas-Garcia for the sample preparation.

${ }^{1}$ T. Shimizu-Iwayama, K. Fujita, S. Nakao, K. Saitoh, T. Fujita, and N. Itoh, J. Appl. Phys. 75, 7779 (1994).

${ }^{2}$ J. G. Zhu, C. W. White, J. D. Budai, S. P. Withrow, and Y. Chen, J. Appl. Phys. 78, 4386 (1995).

${ }^{3}$ A. J. Kenyon, P. F. Trwoga, C. W. Pitt, and G. Rehm, J. Appl. Phys. 79, 9291 (1996).

${ }^{4}$ S. Charvet, R. Madelon, F. Gourbilleau, and R. Rizk, J. Appl. Phys. 85, 4032 (1999).

${ }^{5}$ H. Rinnert, M. Vergnat, G. Marchal, and A. Burneau, Appl. Phys. Lett. 72, 3157 (1998).

${ }^{6}$ M. Molinari, H. Rinnert, and M. Vergnat, Appl. Phys. Lett. 82, 3877 (2003).

${ }^{7}$ M. Zacharias, J. Bläsing, M. Löhmann, and J. Christen, Thin Solid Films 278, 32 (1996).

${ }^{8}$ G. Lucovsky, S. S. Chao, J. Yang, J. E. Tyler, R. C. Ross, and W. Czubatyj, Phys. Rev. B 31, 2190 (1985).

${ }^{9}$ P. G. Pai, S. S. Chao, Y. Takagi, and G. Lucovsky, J. Vac. Sci. Technol. A 4, 689 (1986).

${ }^{10}$ H. Rinnert, M. Vergnat, and A. Burneau, J. Appl. Phys. 89, 237 (2001).

${ }^{11}$ T. Busani, H. Plantier, R. A. B. Devine, C. Hernandez, and Y. Campidelli, J. Non-Cryst. Solids 254, 80 (1999).

${ }^{12}$ T. Busani, H. Plantier, R. A. B. Devine, C. Hernandez, and Y. Campidelli, J. Appl. Phys. 85, 4262 (1999).

${ }^{13}$ G. V. M. Williams, A. Bittar, and H. J. Trodahl, J. Appl. Phys. 67, 1874 (1990).

${ }^{14}$ J. Gonzalez-Hernandez, G. H. Azerbayejani, R. Tsu, and F. H. Pollak, Appl. Phys. Lett. 47, 1350 (1985).

${ }^{15}$ J. H. Chen, D. Pang, H. M. Cheong, P. Wickbolt, and W. Paul, Appl. Phys. Lett. 67, 2182 (1995).

${ }^{16}$ M. V. Wolkin, J. Jorne, P. M. Fauchet, G. Allan, and C. Delerue, Phys. Rev. Lett. 82, 197 (1999).

${ }^{17}$ Y. M. Niquet, G. Allan, C. Delerue, and M. Lanno, Appl. Phys. Lett. 77, $1182(2000)$.

${ }^{18}$ G. Kartopu, S. C. Bayliss, R. E. Hummel, and Y. Ekinci, J. Appl. Phys. 95, 3466 (2004).

${ }^{19}$ S. Takeoka, M. Fujii, S. Hayashi, and K. Yamamoto, Phys. Rev. B 58, 7921 (1998). 